\title{
Editorial
}

\section{The Concept of Euthymia}

\author{
Giovanni A. Fava ${ }^{a}$ b Per Bech $^{c}$ \\ ${ }^{a}$ Department of Psychology, University of Bologna, Bologna, Italy; ${ }^{b}$ Department of Psychiatry, State University of \\ New York at Buffalo, Buffalo, N.Y., USA; ' $P$ sychiatric Research Unit, Psychiatric Centre North Zealand, Copenhagen \\ University Hospital, Hillerød, Denmark
}

When a patient, in the longitudinal course of mood disturbances, no longer meets the threshold of a disorder such as depression or mania, as assessed by categorical methods resulting in diagnostic criteria or by cutoff points in the dimensional measurement of rating scales, he or she is often labeled as euthymic. Bipolar disorder patients spend about half of their time in depression, mania or mixed states [1]. The remaining periods are defined as euthymic. Research identifying the mechanisms that cause the switch to acute mania or depressive episodes has been called for [2]. These efforts have outlined neurocognitive mechanisms [3], structural abnormalities [4], neurotransmitter alterations [5] and sleep disturbances [6]. However, considerable fluctuations in psychological distress, often subsumed under the rubric of subclinical or residual symptomatology, were recorded in studies with longitudinal designs, suggesting that the illness is always active, even though its intensity may vary [7]. Such findings are consistent with the socioeconomic, psychosocial and clinical deterioration in these patients [7]. It is thus questionable whether subthreshold symptomatic periods truly represent euthymia or are simply a part of the manifestations of bipolar illness [7]. Further, with longitudinal designs, considerable variations in biological measurements emerged [8], casting doubts upon the reliability of such measurements for inferring a premorbid or stable state.

\section{KARGER}

(c) 2015 S. Karger AG, Base

0033-3190/15/0851-0001\$39.50/0

E-Mail karger@karger.com

www.karger.com/pps
Similar considerations apply to the use of the term euthymia in unipolar depression and dysthymia, where the overlap with the concept of recovery is considerable [9, 10]. Again, euthymia is often defined essentially in negative terms, as a lack of a certain intensity of mood symptoms, and not as the presence of specific positive features that characterize recovery [9]. This introduces the need for a more comprehensive definition of euthymia.

\section{The Origins of the Concept}

The term euthymia has a Greek origin and results from the combination of 'eu' meaning 'well' and 'thymos' meaning 'soul, emotion'. This latter term encompasses however four different meanings: life energy; feelings and passions; will, desire and inclination; thought and intelligence. Interestingly, its verb (euthymeo) means both I am happy, in good spirits and I make other people happy, I reassure and encourage. The definition of euthymia is generally ascribed to Democritus: one is satisfied with what is present and available, taking little heed of people who are envied and admired and observing the lives of those who suffer and yet endure [11]. It is a state of quiet satisfaction, a balance of emotions that defeats fears. The Latin philosopher Seneca translated the Greek expression of euthymia with 'tranquillitas animi' (a state of internal

Giovanni A. Fava, MD

Department of Psychology, University of Bologna viale Berti Pichat 5

IT-40127 Bologna (Italy)

E-Mail giovanniandrea.fava@unibo.it 
calm and contentment) and linked it to psychological well-being as a learning process. Happiness is not everything and what is required is 'felicitatis intellectus', the awareness of well-being:

Happy is thus the life that is in accordance to its nature, and this is possible only when the mind, first of all, is healthy at any time; then, if it is strong and energetic, definitely patient, capable of mastering everything; concerned with the body and its belongings, but without anxiety; lover of what is life, but with detachment; willing to take advantage of the gifts of fortune, without being its slave. [Seneca: De Vita Beata, translation by G.A.F.]

Plutarch, who attempted a synthesis of Greek and Latin cultures, criticized a concept of euthymia that involves detachment from current events, as portrayed by Epicurus, and underscored the learning potential of mood alterations and adverse life situations.

It took a long time before these concepts were approached in their clinical meanings. In 1958 Marie Jahoda [12] published an extraordinary book on positive mental health. She denied that 'the concept of mental health can be usefully defined by identifying it with the absence of a disease. It would seem, consequently, to be more fruitful to tackle the concept of mental health in its more positive connotation, noting, however, that the absence of disease may constitute a necessary, but not sufficient, criterion for mental health' [12, pp. 14-15]. She outlined criteria for positive mental health: autonomy (regulation of behavior from within), environmental mastery, satisfactory interactions with other people and the milieu, the individual's style and degree of growth, development or self-actualization, the attitudes of an individual toward his/her own self (self-perception/acceptance).

In the first edition of his Personality and Adjustment [13] Lazarus referred to the writings of Jahoda [12] especially focusing on her view that a competent person is better adjusted than an incompetent one to manage interpersonal relationships and to succeed in self-development in an individually chosen direction. In his monograph on Psychological Stress and the Coping Process [14], Lazarus introduced the term 'eustress' ('good stress') to underline the positive cognitive response to stress to be identified in healthy competent people as defined by Jahoda [12]. When summarizing his 40 years of stress research, Selye [15] used the term 'eustress'. He concluded [16] that it is not possible to suppress stress in all forms, but the goal of each person is to diminish distress and to facilitate eustress, the psychological sensation of well-being. In 1991, Garamoni et al. [17] suggested that healthy functioning is characterized by an optimal balance of positive and negative cognitions or affects and that psychopathology is marked by deviations from the optimal balance. As pointed out by Wood and Tarrier [18], also excessively elevated levels of positive emotions can become detrimental and are more connected with mental disorders and impaired functioning.

Ryff [19] derived her model of psychological well-being from Jahoda's first 5 dimensions of positive functioning, which were slightly reworded, and introduced a method for their assessment, the Psychological Well-Being scales (PWB). Jahoda, however, also outlined a characteristic that was very much related to the concept of euthymia which was defined as integration: the individual's balance of psychic forces (flexibility), a unifying outlook on life which guides actions and feelings to shape the future accordingly, and resistance to stress (resilience and anxiety or frustration tolerance). It is not simply a generic (and clinically useless) effort of avoiding excesses and extremes. It is how the individual adjusts the psychological dimensions of well-being to changing needs. Unfortunately Ryff missed the euthymia component of Jahoda's model [12] in putting together the PWB.

In recent years, there has been an increasing interest in the concept of flexibility, which revives Jahoda's conceptualizations [12]. Kashdan and Rottenberg [20] view psychological flexibility as the ability to recognize and adapt to various situational demands; to change one's paradigms when these strategies compromise personal or social functioning; to maintain balance among important life domains, and to display consistency in one's behavior and deeply held values. The absence of flexibility is likely to yield depression, anxiety and the general tendency to experience negative emotions more frequently, intensely, and readily, for more enduring periods of time, in what has been subsumed under the rubric of neuroticism [20]. Tyrer et al. [21] remarked that what is shared by syndromes such as anxiety, panic, phobic disturbances and irritability may be as important as the differences between them, and conditions that are apparently comorbid could be part of the same clinical syndrome. They argued that the combination of mixed anxiety and depressive disorders together with a certain type of abnormal personality (excessive timidity, poor self-esteem, avoidance of anxiety-provoking situations and dependence on others) constitutes a single syndrome, the general neurotic syndrome [21]. This syndrome was shown to be associated with a poor response to treatment, a frequency of symptoms throughout the neurotic diagnostic spectrum and a tendency to relapse. The concept of neurosis, in its phenomenological [22] and psychodynamic [23] traditions, still has a lot to teach us in terms of clinical thinking [24]. It is 
interesting that Eysenck [25] referred to neuroticism and introversion by the term of dysthymia. In his neuroticism scale, The Maudsley Medical Questionnaire, Eysenck [25] included the dysthymic components of depression, anxiety and interpersonal sensitivity, but also sleep items. In 1967, covering the biological basis of personality, he showed that when compared to normal controls, persons with high neuroticism scores (dysthymics) had significantly higher waking pulse rates, indicating nonrestorative sleep [26].

\section{Definition and Measurement}

A state of euthymia appears to be characterized by the following features:

(a) Lack of mood disturbances that can be subsumed under diagnostic rubrics; if the subject has a prior history of mood disorder, he/she should be in full remission. If sadness, anxiety or irritable mood are experienced, they tend to be short-lived, related to specific situations and do not significantly affect everyday life.

(b) The subject feels cheerful, calm, active, interested in things and sleep is refreshing or restorative.

(c) The subject displays balance and integration of psychic forces (flexibility), a unifying outlook on life which guides actions and feelings to shape the future accordingly, and resistance to stress (resilience and anxiety or frustration tolerance).

While there have been considerable efforts to quantify and qualify psychological distress [27], relatively little has been done about assessing the positive components of euthymia (point c). One could qualify it as a lack of or as low levels of neurotic behavior, but this approach is not entirely satisfactory. There are several instruments to assess well-being states and dimensions $[28,29]$. In particular, the WHO-5 Well-Being Index $[27,30]$ appears to cover point $b$ of our operational definition of Jahoda's euthymia. Single aspects of the interplay that is described under point $c$ can be assessed. For instance, a 10-item selfrating scale, the Acceptance and Action Questionnaire (AAQ-II) to measure psychological flexibility, has been developed [31,32]. Yet, flexibility is only one component of euthymia. Table 1 outlines a scale that characterizes euthymia, using clinimetric principles [27, 33] which avoid any form of redundancy. The last 5 items of the scale are derived from the WHO-5 index [30].

This definition of euthymia incorporates Selye's concept of eustress $[15,16]$. Because of its intertwining with mood stability, it is substantially different from the con-
Table 1. Euthymia scale

$\begin{array}{llll}1 & \begin{array}{l}\text { If I become sad, anxious or angry it is for a } \\ \text { short time }\end{array} & \text { TRUE } & \text { FALSE } \\ 2 & \begin{array}{l}\text { I do not keep thinking about negative } \\ \text { experiences }\end{array} & \text { TRUE } & \text { FALSE } \\ 3 & \begin{array}{l}\text { I am able to adapt to changing situations } \\ 4\end{array} & \text { TRUE } & \text { FALSE } \\ \text { behaviors } & \text { TRUE } & \text { FALSE } \\ 5 & \text { Most of the time I can handle stress } & \text { TRUE } & \text { FALSE } \\ 6 & \text { I generally feel cheerful and in good spirits } & \text { TRUE } & \text { FALSE } \\ 7 & \text { I generally feel calm and relaxed } & \text { TRUE } & \text { FALSE } \\ 8 & \text { I generally feel active and vigorous } & \text { TRUE } & \text { FALSE } \\ 9 & \begin{array}{l}\text { My daily life is filled with things that } \\ \text { interest me }\end{array} & \text { TRUE } & \text { FALSE } \\ 10 & \text { I wake up feeling fresh and rested } & \text { TRUE } & \text { FALSE }\end{array}$

Each item can be scored as 1 (TRUE) or 0 (FALSE), with a total range of $0-10$.

cept of eudaimonic well-being that has become increasingly popular in positive psychology [34]. Ryan and Deci [35] have summarized research on psychological well-being as falling in two general groups: the hedonic viewpoint focuses on subjective well-being, happiness, pain avoidance and life satisfaction, whereas the eudaimonic viewpoint, as portrayed by Aristotle, focuses on meaning and self-realization and defines well-being in terms of the degree to which a person is fully functioning or as a set of wellness variables such as self-actualization and vitality. However, the two viewpoints are inextricably linked in clinical situations, where they also interact with mood fluctuations [36]. The eudaimonic perspective thus ignores the complex balance of positive and negative affects in psychological disturbances $[17,18]$.

\section{Clinical Implications}

There are several clinical implications that may derive from the assessment of euthymia in positive terms and not simply as the absence of the acute manifestation of a disorder as in bipolar illness [1-6].

The first implication is concerned with the targets of treatment. There are psychotherapeutic treatments that are geared to a state of euthymia. A specific psychotherapeutic strategy for increasing psychological well-being, well-being therapy (WBT), was found to be an effective ingredient in a number of randomized controlled clinical trials $[36,37]$. It is based on Jahoda's model of psycho- 
logical well-being [12]. The findings indicate that optimal human functioning can be promoted by WBT leading to a positive evaluation of one's self, a sense of continued growth and development, the belief that life is purposeful and meaningful, the possession of quality relations with others, the capacity to manage effectively one's life, a sense of self-determination, and psychological flexibility $[36,37]$. Such modifications are associated with enduring benefits, as was found to be the case in three randomized controlled trials aimed to reducing recurrence in depression [38-40]. Another psychotherapeutic strategy, acceptance and commitment therapy, purports to increasing psychological flexibility [32]. There are many other psychological therapies that pertain to positive psychology which are aimed to increasing psychological well-being [41], yet they entail the risk of being oversimplistic efforts which are likely to clash with clinical reality. Disregard of the concept of euthymia may lead in fact to targeting inappropriately elevated levels of positive emotions that can become detrimental [18] and to disruption of the complex balance of well-being and distress [17, 42]. An additional novel area in psychotherapy research can ensue from exploring euthymia as a characteristic of successful psychotherapists, as the Greek verb equivalent implies.

Important sources of information may derive from the application of a comprehensive concept of euthymia to the study of remission and recovery in mood disorders [9] and of vulnerability to depression in anxiety disturbances [43]. Why do many patients in the longitudinal course of anxiety disorders develop depression and other patients do not? It is of interest that when WBT was applied to generalized anxiety disorder, it yielded better results than standard cognitive behavior therapy [44].

There has been growing awareness of the fact that traumatic experiences can also give rise to positive transformations, the posttraumatic growth [45]. Positive changes can be observed in self-concept (e.g., new evaluation of one's strength and resilience), appreciation of new possibilities in life, social relations, hierarchy of values and priorities, and spiritual growth [45]. Plutarch's view of euthymia may encompass these phenomena, being at the same time more comprehensive in clinical settings, since the trigger does not need to be traumatic. In posttraumatic stress disorder nonrestorative sleep is the very first symptom to emerge, and if it is not recognized, an increased risk of depression or dysthymia may ensue [27]. Restorative sleep is a homeostatic or allostatic factor, enabling the organism to achieve positive mental health and is among the most significant contributors in the assessment of euthymia [29]. It is measured by the item of waking up feeling fresh and rested (table 1). Lack of restorative sleep may also be seen in depressed patients treated with antidepressant medication [46]. Specific psychotherapies focusing on restorative sleep are under development.

Finally, there might be important applications of the concept of euthymia in the setting of medical disease. There has been recent interest in the relationship between psychological flexibility and chronic pain [47]. Euthymia may affect how a person experiences the disease process.

We thus encourage investigators to take advantage of the insights of Greek and Latin philosophers and of Jahoda when addressing the concept of euthymia in clinical research. As a construct of positive mental state, euthymia has to capture the items listed in table 1, i.e. living autonomously but with deep personal relationships, being cheerful and calm, feeling useful and active, and obtaining restorative sleep.

\section{Disclosure Statement}

The authors have no conflicts of interest to disclose.

\section{References}

1 Judd LL, Akiskal HS, Schettler PJ, Endicott J, Maser J, Solomon DA, Leon AC, Rice JA, Keller MB: The long-term natural history of the weekly symptomatic status of bipolar I disorder. Arch Gen Psychiatry 2002;59:530537.

$\checkmark 2$ Blumberg HP: Euthymia, depression, and mania: what do we know about the switch? Biol Psychiatry 2012;71:570-571.
Martini DJ, Strejilevich SA, Marengo E, Ibanez A, Scapola M, Igoa A: Toward the identification of neurocognitive subtypes in euthymic patients with bipolar disorder. J Affect Disord 2014;167:118-124.

4 Canales-Rodriguez EJ, Pomarol-Clotet E, Radua J, Sarro S, Alonso-Lana S, Del Mar Bonnin C, Goikolea JM, Maristany T, GarciaAlvarez R, Vieta E, McKenna P, Salvador R: Structural abnormalities in bipolar euthymia. Biol Psychiatry 2014;76:239-248.
5 Hannestad JO, Cosgrove KP, Dellagioia NF, Perkins E, Bois F, Bhagwagar Z, Seybyl JP, McClure-Begley TD, Picciotto MR, Esterlis I: Changes in the cholinergic system between bipolar depression and euthymia as measured with ${ }^{123}$ I 5IA single photon emission computed tomography. Biol Psychiatry 2013;74:768776.

-6 Rocha PM, Neves FS, Correa H: Significant sleep disturbances in euthymic bipolar patients. Comp Psychiatry 2013;54:1003-1008. 
7 Fava GA: Subclinical symptoms in mood disorders: pathophysiological and therapeutic implications. Psychol Med 1999;29:47-61.

-8 Fava GA, Molnar G, Spinks M, Loretan A, Edwards L, Morphy MA: Case report of prolactin and bipolar illness: a longitudinal study. Prog Neuropsychopharmacol Biol Psychiatry 1985;9:451-457.

-9 Fava GA, Ruini C, Belaise C: The concept of recovery in major depression. Psychol Med 2007;37:307-317.

10 Dunner DL: Duration of periods of euthymia in patients with dysthymic disorder. Am J Psychiatry 1999;156:1992-1993.

11 Kahn CH: Democritus and the origins of moral psychology. Am J Philol 1985;106:131.

12 Jahoda M: Current Concepts of Positive Mental Health. New York, Basic Books, 1958.

13 Lazarus RS: Personality and Adjustment. Upper Saddle River, Prentice-Hall, 1963.

14 Lazarus RS: Psychological Stress and the Coping Process. New York, McGraw-Hill, 1966.

15 Selye H: Stress without Distress. New York, Lippincott, 1974.

16 Selye H: Further thoughts on 'stress without distress'. Med Times 1976;104:124-144.

17 Garamoni GL, Reynolds CF III, Thase ME: The balance of positive and negative affects in major depression: a further test of the states of the mind model. Psychiatry Res 1991;39:99108.

$\checkmark 18$ Wood AM, Tarrier N: Positive clinical psychology. Clin Psychol Rev 2010;30:819-829.

19 Ryff CD: Happiness is everything, or is it? Explorations on the meaning of psychological well-being. J Pers Soc Psychol 1989;6:10691081.

20 Kashdan TB, Rottenberg J: Psychological flexibility as a fundamental aspect of health. Clin Psychol Rev 2010;30:865-878.

-21 Tyrer P, Seivewright N, Ferguson B, Tyrer J: The general neurotic syndrome. Acta Psychiatr Scand 1992;85:201-206.

22 Slater E, Slater P: A heuristic theory of neurosis. J Neurol Psychiatry 1944;7:49-55.

23 Taylor GJ: Affects, trauma, and mechanisms of symptom formation. A tribute to John C. Nemiah, MD (1918-2009). Psychother Psychosom 2010;79:339-349.
24 Fava GA, Rafanelli C, Tomba E: The clinical process in psychiatry. J Clin Psychiatry 2012; 73:177-184.

25 Eysenck HJ: The Scientific Study of Personality. London, Routledge \& Kegan, 1952.

26 Eysenck HJ: The Biological Basis of Personal ity. Springfield, Thomas, 1967, p 285.

27 Bech P: Clinical Psychometrics. Oxford, Wiley Blackwell, 2012.

28 Rafanelli C, Ruini C: Assessment of psychological well-being in psychosomatic medicine; in Fava GA, Sonino N, Wise TN (eds): The Psychosomatic Assessment. Basel, Karger, 2012, pp 182-202.

29 Bech P: Clinical assessments of positive mental health; in Jeste DV, Palmer BW (eds): Positive Psychiatry. Washington, American Psychiatric Publishing, 2015, pp 127-143.

30 Topp CW, Ostergaard SD, Sondergaard S, Bech P: The WHO-5 Well-Being Index: a systematic review of the literature. Psychother Psychosom 2015;84:167-176.

31 Bond FW, Hayes SC, Baer R, Carpenter KM, Guenole N, Orcutt HK, Waltz T, Zettle RD: Preliminary psychometric properties of the Acceptance and Action Questionnaire II: a revised measure of psychological inflexibility and experiential avoidance. Behav Ther 2011; 42:676-688.

32 Fledderus M, Bohlmeijer ET, Fox JP, Schreurs KMG, Spinhoven P: The role of psychological flexibility in a self-help acceptance and commitment therapy intervention for psychological distress in a randomized controlled trial. Behav Res Ther 2013;51:142-151.

33 Fava GA, Tomba E, Sonino N: Clinimetrics: the science of clinical measurements. Int $J$ Clin Pract 2012;66:11-15.

34 Huta V: Eudaimonia; in David SA, Boniwel I, Conley Ayers A (eds): The Oxford Handbook of Happiness. Oxford, Oxford University Press, 2013, pp 200-213.

35 Ryan RM, Deci EL: On happiness and human potential: a review of research on hedonic and eudaimonic well-being. Annu Rev Psychol 2001;52:141-166.

36 Fava GA, Tomba E: Increasing psychological well-being and resilience by psychotherapeutic methods. J Pers 2009;77:1902-1934.

- 37 Fava GA: Well-Being Therapy. Treatment Manual and Clinical Applications. Basel, Karger, 2016.
8 Fava GA, Ruini C, Rafanelli C, Finos L, Conti S, Grandi S: Six-year outcome of cognitive behavior therapy for prevention of recurrent depression. Am J Psychiatry 2004;161:18721876.

39 Stangier U, Hilling C, Heidenreich T, Risch AK, Barocka A, Schlösser R, Kronfeld K, Ruckes C, Berger H, Röschke J, Weck F, Volk S, Hambrecht M, Serfling R, Erkwoh R, Stirn A, Sobanski T, Hautzinger M: Maintenance cognitive-behavioral therapy and manualized psychoeducation in the treatment of recurrent depression: a multicenter prospective randomized controlled trial. Am J Psychiatry 2013; 170:624-632.

40 Kennard BD, Emslie GJ, Mayes TL, Nakonezny PA, Jones JM, Foxwell AA, King J: Sequential treatment with fluoxetine and relapse-prevention CBT to improve outcomes in pediatric depression. Am J Psychiatry 2014; 171:1083-1090.

41 Rashid T: Positive psychology in practice: positive psychotherapy; in David SA, Boniwell I, Conley Ayers A (eds): The Oxford Handbook of Happiness. Oxford, Oxford University Press, 2013, pp 978-993.

42 Rafanelli C, Park SK, Ruini C, Ottolini F, Cazzaro M, Grandi S, Fava GA: Rating well-being and distress. Stress Med 2000;16:55-61.

43 Fava GA, Tomba E: Treatment of comorbid anxiety disorders and depression; in Emmelkamp PMG, Ehring T (eds): The Wiley Handbook of Anxiety Disorders. Chichester, Wiley, 2014, vol 2, pp 1165-1182.

- 44 Fava GA, Ruini C, Rafanelli C, Finos L, Salmaso L, Mangelli L, Sirigatti S: Well-being therapy of generalized anxiety disorder. Psychother Psychosom 2005;74:26-30.

45 Tedeschi RG, Calhoun LG: The Posttraumatic Growth Inventory. J Trauma Stress 1996;9: 455-471.

46 Ellervik C, Kvetny J, Bech P: The relationship between sleep length and restorative sleep in major depression: results from the Danish General Suburban Population Study. Psychother Psychosom 2016;85:45-46.

47 McCracken LM, Morley S: The psychological flexibility model: a basis for the integration and progress in psychological approaches to chronic pain management. J Pain 2014;15: 221-234. 